\title{
Interdependent intercultural task as a tool for developing intercultural awareness through Collaborative Online International Learning in Global Leadership
}

\author{
Lori M. Curtindale', Svetlana G. Krylova ${ }^{2}$, and Svetlana A. Minyurova ${ }^{3}$
}

\section{Abstract}

his paper discusses a teaching approach that can be used in Collaborative Online International Learning (COIL) - Interdependent Intercultural Tasks (IIT). IIT are

characterized by the following features: (1) they include culture-specific information that creates cognitive dissonance and motivates students to analyze information about another culture; (2) they provide instructions aimed at learning subjective information about individuals from another culture; and (3) they can only be performed through interaction between students from different countries. We expect two learning outcomes of implementing IIT in a Global Leadership course; an increase in (1) intercultural interaction when working on a collaborative project; and (2) awareness of general cultural differences and those related to a specific global problem. Preliminary findings suggest that employing IIT (i.e. having students discuss native and non-native country media articles describing culture-specific perspectives on a global problem) increases the frequency of student interactions outside the classroom and improves coordination between teammates.

\section{Keywords: online international learning; intercultural awareness; global leadership.}

1. Department of Psychology, Lycoming College; curtindale@lycoming.edu; https://orcid.org/0000-0002-0551-919X

2. Psychological Department, Ural State Pedagogical University; krylovas@uspu.me; https://orcid.org/0000-0002-2089-7885

3. Psychological Department, Ural State Pedagogical University; s.minyurova@mail.ru; https://orcid.org/0000-0003-3852-0434

How to cite this article: Curtindale, L. M., Krylova, S. G., \& Minyurova, S. A. (2020). Interdependent intercultural task as a tool for developing intercultural awareness through Collaborative Online International Learning in Global Leadership. Journal of Virtual Exchange, 3(SI-IVEC2019), 81-92. https://doi.org/10.21827/jve.3.35803 


\section{Introduction}

COIL has become a common form of learning in higher education. An important advantage of this type of learning is the opportunity for students to gain intercultural experience without leaving their current place of residence and university. Student participation in online exchange is also appealing because it requires less financial and organizational effort compared to traditional student exchange programs (Guth, 2014). These factors are relevant for students of state universities (i.e. East Carolina University (ECU), USA and Ural State Pedagogical University (USPU), Russia) who are first-generation, lower or middle income, and/or from small towns or rural areas.

A primary goal of COIL is to increase students' ability to communicate effectively in intercultural interactions (i.e. intercultural competence). Participation in COIL is the only opportunity many students have for intercultural interaction and to become competent citizens of the modern global world. Nevertheless, organizers of COIL have noted challenges in implementation (i.e. incorporating and assessing the development of intercultural awareness) and student collaboration (resistance when prompted to use email and Skype to communicate and collaborate outside of class time, Guth, 2014). Therefore, it is important to consider factors (e.g. team development) that may increase the effectiveness of implementation of COIL and student experiences during intercultural collaboration (Minyurova, Krylova, \& Rudenko, 2015).

This paper focuses on the analysis of tasks used in COIL to stimulate intercultural interaction between students and allow them to gain knowledge about another culture. Students enrolled in a course on Global Leadership (ECU in Greenville, North Carolina, USA, and USPU in Yekaterinburg, Russia) completed collaborative team projects; they selected a global problem and developed solutions for the problem while considering the cultural specifics of each country (USA and Russia). We outline the process of developing and implementing an IIT and report on the impact of the IIT on intercultural interaction during the collaborative project and awareness of general cultural differences and those related to a specific global problem.

\section{Context}

Global Leadership is an elective, COIL course co-taught by two professors at ECU (USA) and USPU (Russia). The course provides an overview of major leadership theories and practices from a global perspective. This pilot project included students participating in Global Leadership during the spring semesters of 2018 and 2019 (Table 1). The course of study for the majority of ECU students was psychology, while all USPU students were studying English, through Foreign Languages or History. 
The course was taught in English; the native languages for ECU and USPU students were English and Russian, respectively. The majority of USPU students were proficient in English at an intermediate mid- to advanced mid-level.

Table 1. ECU and USPU student information for 2018 and 2019 academic years

\begin{tabular}{|c|c|c|}
\hline & \multicolumn{2}{|l|}{ Academic year } \\
\hline & 2018 & 2019 \\
\hline ECU students & 12 (75\% female) & 13 (85\% female) \\
\hline Courses of study & $\begin{array}{l}\text { Psychology (67\%) } \\
\text { Other (33\%) }\end{array}$ & $\begin{array}{l}\text { Psychology (69\%) } \\
\text { Other }(31 \%)\end{array}$ \\
\hline Stage of Study & $\begin{array}{l}\text { Year } 1(0 \%) \\
\text { Year } 2(8 \%) \\
\text { Year } 3(50 \%) \\
\text { Year } 4(42 \%)\end{array}$ & $\begin{array}{l}\text { Year } 1(15 \%) \\
\text { Year } 2(0 \%) \\
\text { Year } 3(31 \%) \\
\text { Year } 4(54 \%)\end{array}$ \\
\hline USPU students & 7 (86\% female) & 7 (100\% female) \\
\hline Courses of study & $\begin{array}{l}\text { Foreign Languages-English (43\%) } \\
\text { History \& English (57\%) }\end{array}$ & $\begin{array}{l}\text { Foreign Languages-English (43\%) } \\
\text { History \& English (57\%) }\end{array}$ \\
\hline Stage of Study & \begin{tabular}{|l} 
Year $1(0 \%)$ \\
Year $2(43 \%)$ \\
Year $3(0 \%)$ \\
Year $4(57 \%)$
\end{tabular} & $\begin{array}{l}\text { Year } 1(14 \%) \\
\text { Year } 2(29 \%) \\
\text { Year } 3(57 \%) \\
\text { Year } 4(0 \%)\end{array}$ \\
\hline English Proficiency & $\begin{array}{l}\text { Intermediate low (14\%) } \\
\text { Intermediate mid (43\%) } \\
\text { Advanced mid (43\%) }\end{array}$ & $\begin{array}{l}\text { Intermediate low (14\%) } \\
\text { Intermediate mid (72\%) } \\
\text { Advanced mid (14\%) }\end{array}$ \\
\hline
\end{tabular}

\section{Objectives}

For students to acquire intercultural experience it is necessary for them to interact with people from another culture. Through COIL, these intercultural interactions take place in a virtual form. Despite virtual interaction being a part of modern life (in countries with developed economies), participating in virtual exchange does not guarantee students a meaningful intercultural experience. Research and practice have identified common communication, cultural, technical, and language issues of virtual exchange (EVALUATE Group, 2019). One of the most challenging aspects of intercultural communication through virtual exchange is encouraging deep level student engagement, especially with cultural differences (EVALUATE Group, 2019, O’Dowd \& Ritter, 2006). Without support, students often engage with exchange partners on a surface level, ignoring or minimizing cultural differences. Although this superficial approach helps reduce miscommunication, when students learn to reflect 
on the complexity of cultural differences they gain valuable opportunities for intercultural learning (EVALUATE Group, 2019, O’Dowd \& Ritter, 2006).

Thus, the first aim of this pilot project was to create a task that could be used in COIL to stimulate intercultural interaction between students and allow them to gain knowledge about another culture - an IIT. The motivation for developing IIT was our four semesters of experience in teaching the Global Leadership course and the challenges we faced (Curtindale \& Krylova, 2019). In Global Leadership, students completed collaborative projects, identifying a global problem where the application of leadership principles will lead to meaningful change. The results of each team's work are presented in the form of a PowerPoint presentation. Although each team completes a common final project, individual students may prepare their own part of the presentation (from the native culture point of view), which does not require interaction with partners from another country. While the final project is formally a collaborative one, it may be only the sum of the parts performed by each student independently from the team. This limits participants' intercultural interaction experience, which is the essence of COIL. Therefore, we set a goal to develop a task that requires interaction between students from different countries and allows students to be open to new information, taking more than one perspective, and understanding personal ways of interpreting messages and situations. These skills are consistent with the description the ethno-relative stages in the developmental model of intercultural sensitivity (Bennett, 1986), which "refer to issues associated with experiencing all cultures as alternative ways of organizing reality” (Bennett, 2017, p. 3).

When designing the IIT, we considered two assumptions.

- In any culture, there are both universal (e.g. objects and processes common for many cultures) and culture-specific information. Culture-specific information is familiar to people of one culture, but it creates dissonance for people of another culture. Individuals are motivated to reduce the discrepancy between their beliefs and this new knowledge about another culture (i.e. cognitive dissonance; Festinger, 1957). Culturally specific communication motivates individuals from another culture to analyze and interpret information to explain the differences between cultures. Thus, our first conclusion is that IIT should include culturespecific information that creates cognitive dissonance and motivates students to analyze information about another culture; and

- Informational technologies allow students to find objective information about any country without intercultural interaction. This information expands their knowledge about another culture but does not increase intercultural competence because objective information is interpreted from the perspective of the students' culture. To understand information from the perspective of another culture, it is necessary for students to know how it is interpreted, 
subjectively, by individuals from that culture. This subjective information can best be obtained through interaction with individuals from another culture. Therefore, our second conclusion is that IIT should provide instructions aimed at learning subjective information about individuals from another culture.

Based on these assumptions, we formulated and implemented IIT during the spring 2019 semester of our Global Leadership course. In this pilot study, we examine the effect of the IIT by comparing the frequency and quality of intercultural team interactions during the 2018 and 2019 academic years.

\section{Project design}

The collaborative portion of Global Leadership is typically held during the spring semester (February-April, when university schedules align) for approximately eight weeks. Students meet twice a week for one hour, on Tuesdays and Thursdays, via videoconference. On Tuesdays (whole class link) a teacher from ECU or USPU lectures to all students on various aspects of leadership, and teams report on their discussions from the previous week. On Thursdays (team link), students work virtually in small intercultural teams of three to four people - typically two or three ECU students and one or two USPU students. The course includes seven, one-hour team link classes. During team links, students are instructed to discuss three types of issues: (1) the content of the previous lecture; (2) cultural differences between Russia and the USA (general attitudes, social norms, and traditions), using CultureGrams (ProQuest, 2019a, 2019b); and (3) the topic chosen by the team for the collaborative project. Students are encouraged to communicate with their teammates outside of class using the team's preferred communication tools (e.g. email, WhatsApp, Telegram, Facebook, Instagram, Twitter, Facebook, Skype). The frequency and duration of communication between classes are determined by students and are not controlled by the teachers. Reported in the end of semester survey, the frequency of communication between classes ranged from 'only in the classroom' to '2-3 times a week' (see Figure 2).

During the 2019 academic year, we incorporated IIT into the collaborative team project. After teams selected a global problem (Table 2), each student found articles, in the native country media, that described culture-specific situations and reflected behavior in daily lives. Russian students translated the selected articles from the Russian media into English. The literal translation was not required - it was only necessary to reflect the essence of the article. The Russian teacher checked the correspondence of the translation to the content of the article. For Russian students, this additional work was part of the course requirements. Students from the partner university read the articles/ translations and chose one that was most surprising to them (i.e. culture-specific). Students who 
selected the articles interviewed their partners to identify attitudes about the culture-specific situation. Additionally, a reflective question, answered by interviewees and then interviewers, allowed interviewees to assess the accuracy of their assumptions. The results of the IIT were represented in collaborative presentations (i.e. American and Russian teammates presented as one team). Figure 1 is an excerpt from the collaborative project guidelines provided to teams at the beginning of the semester. At the end of the semester, students were surveyed using an anonymous Google-form questionnaire (Krylova \& Curtindale, 2017). First, students indicated their team number, then they answered 24 questions distributed in six clusters: (1) general information about the composition of the teams; (2) communication tools; (3) interaction between members of the teams; (4) satisfaction with the work in a team; (5) relationships in the teams; and (6) participation of team members in teamwork.

\section{Table 2. Collaborative project topics (2019)}

\begin{tabular}{|l|l|l|l|}
\hline Team & ECU students & USPU students & Collaborative project topic \\
\hline 1 & 3 & 1 & School shootings \\
\hline 2 & 2 & 2 & Growing influence of mass and social media \\
\hline 3 & 2 & 1 & Social Media and mental health \\
\hline 4 & 2 & 1 & Vaccination refusal \\
\hline 5 & 2 & 1 & Substance abuse and mental illness \\
\hline 6 & 2 & 1 & Stress and anxiety among college students \\
\hline
\end{tabular}

\section{Figure 1. Project guidelines specific to the IIT}

\section{PROJECT GUIDELINES}

\section{Identification of culture-specific attitudes regarding the selected problem}

1 Find, in the media of your country, at least 3 articles from the native country media that describe culturespecific situations relevant to the selected problems (e.g. for the problem "Gun incidents in schools", ECU students might choose an article about teachers carrying guns in and around schools in Arkansas). Articles should have specific information about the behavior of people in their daily lives.

2 Ask teammates from the partner university to choose the article that is most surprising or unusual to them.

3 Explore and identify attitudes of your teammates regarding the culture-specific situation, asking them questions (e.g. Is such a situation possible in your country? Why yes (or why not)?). Write down their answers briefly.

4 Ask your teammates to guess how people in your country evaluate this situation. Write down their answers briefly. Answer this question yourself to give your teammate an opportunity to assess the accuracy of his or her assumption. 
$5 \quad$ Present the results of this task in the final presentation (don't forget to accompany the answers with arguments), including:

- description of the culture-specific situation (which was chosen by your teammates);

- brief answers of your teammates; and

- comparison of your teammates' assumptions and your answer.

[ 1-3 slides of the presentation]

\section{Evaluation of outcomes}

We expected two learning outcomes of using the IIT; an increase in the frequency and quality of intercultural interaction when working on a collaborative project, and an increase in awareness of general cultural differences and those related to a specific global problem. To investigate these learning outcomes, we compared end of the semester survey results of students enrolled in Global Leadership in 2018 and 2019 (Table 1). During both academic years, students were trained on the same syllabus with one notable difference - in 2019 students performed the IIT.

Before making quantitative comparisons, we explored content and quality of the IIT during the 2019 academic year. The IIT formulation included several steps (Figure 1). Because we implemented the IIT for the first time during the 2019 academic year, we did not expect all teams to complete the task perfectly. Indeed, based on our qualitative analysis (Table 3) and observations of team performance, only $50 \%$ of the teams incorporated all aspects of the IIT into their final presentation. As can be seen in Table 3, all six teams found articles relevant to the topic of their collaborative project. However, half of the articles did not contain culturally specific information and had generalized content, that is, they did not describe the behavior of people in their daily lives. It may not have been clear to teams what kind of articles they needed to find (despite the example provided about carrying guns by American teachers in Arkansas). There was also a culturally specific challenge; Russian students had to find appropriate articles and translate the essence of these articles into English. Additionally, for some collaborative project topics students reported that they could not find articles that would satisfy the requirements formulated for IIT.

Another step of the IIT was to select an article with content that seemed most surprising to partners (we considered surprise as an emotional reaction to the cultural specificity of information). We did not control whether teams complied with this requirement. However, given the similar attitudes of American and Russian students regarding the content of the article reported in the team presentation (e.g. Table 4), this guideline was likely not met by all teams. One of the USPU students found an 
article in the Russian media about viral parties for children (as if it is a Russian phenomenon) and wrote that she herself was "shocked" (Table 4) when she read about it. Interestingly, some Russian media report that the tradition of viral parties for children came from the United States. Therefore, the surprise of a Russian student is just a reaction to a culturally specific situation that initially arose not in Russia, but in the United States.

Table 3. Qualitative analysis team IIT performance

\begin{tabular}{|c|c|c|c|c|c|c|}
\hline \multirow[t]{2}{*}{ IIT performance characteristics } & \multicolumn{6}{|c|}{ Teams } \\
\hline & 1 & 2 & 3 & 4 & 5 & 6 \\
\hline $\begin{array}{l}\text { Articles (including title, description) relevant to the } \\
\text { topic of a collaborative project are presented }\end{array}$ & + & + & + & + & + & + \\
\hline $\begin{array}{l}\text { Presentation includes at least one article describing a } \\
\text { specific situation from the everyday life of people }\end{array}$ & & + & + & + & & \\
\hline $\begin{array}{l}\text { Feedback from ECU and USPU students, reflecting their } \\
\text { attitudes about the problem, is presented for each article }\end{array}$ & & + & + & + & + & \\
\hline
\end{tabular}

Table 4. Comparison of American and Russian students' culture-specific attitudes regarding the selected problem (excerpt from the final presentation on the topic vaccination refusal)

\begin{tabular}{|l|l}
\hline United States & Russia
\end{tabular}

ECU selected article: An Unvaccinated Boy Got Tetanus. His Oregon Hospital Stay: 57 Days and \$800,000 (Mervosh, 2019)

\begin{tabular}{|l|l} 
"It could happen again because people are stubborn.” & "This could happen because a lot of parent refuse vaccines.”
\end{tabular}

"It makes us frustrated because tetanus is a

completely preventable disease and it caused him

so much pain/his parents so much money."

USPU selected article: The so-called viral parties are gaining popularity in Russia (Onishchenko, 2019)

"We heard this happening in the USA and it sounds crazy."

"This brings more harm to the child than

a vaccination would bring."
"Didn't know this happened, shocked."

"Think it could happen more in Russia and be continued until a lot of children die.”

The final and most important part of the IIT involves interviewing partners regarding culturally specific articles. The implementation of this part is necessary to compare the points of view of students from different countries. In the final presentations, four of the six teams clearly reported the opinions of students from Russia and the USA allowing for comparison. However, these opinions are quite general and similar, reducing their value for expanding the cultural experience. Additionally, none of the teams presented answers to such questions as: 'Is such a situation possible in your country? Why yes (or why not)?'. Perhaps students interviewed each other during the team link classes, but they did not report the results of the interviews in their final presentations (as recommended in point 5 of Project guidelines specific to the IIT - Figure 1). 
The quantitative indicators presented in Figure 2 and Figure 3 demonstrate an improvement in intercultural interaction in the 2019 group that performed the IIT. In this group, the number of students who interacted with their partners only in the classroom decreased, and the number of students who interacted 2-3 times a week increased (Figure 2). In addition, none of the students chose the answer 'each of us worked independently on his/her part of the project', and more students chose the answer 'we constantly coordinated with each other on all our actions' (Figure 3). However, more students in the 2019 group rated the relations in the group as 'neutral' and 'business than friendly’ (Figure 4).

The validity of the obtained results has a number of limitations: (1) we did not evaluate the equivalence of the groups before the start of Global Leadership; therefore, the difference in the survey results may be due to both initial difference between the groups and the use of IIT; (2) the limited sample size reduces the degree of generalization of the results; (3) we evaluated only changes in the activity of intercultural interaction of students, the assessment of changes in intercultural awareness is a future task; and (4) we did not use any statistical criteria for quantitative analysis of the results.

Figure 2. Distribution of students' answers to the question 'How often did your team discuss work on the project between classes?'

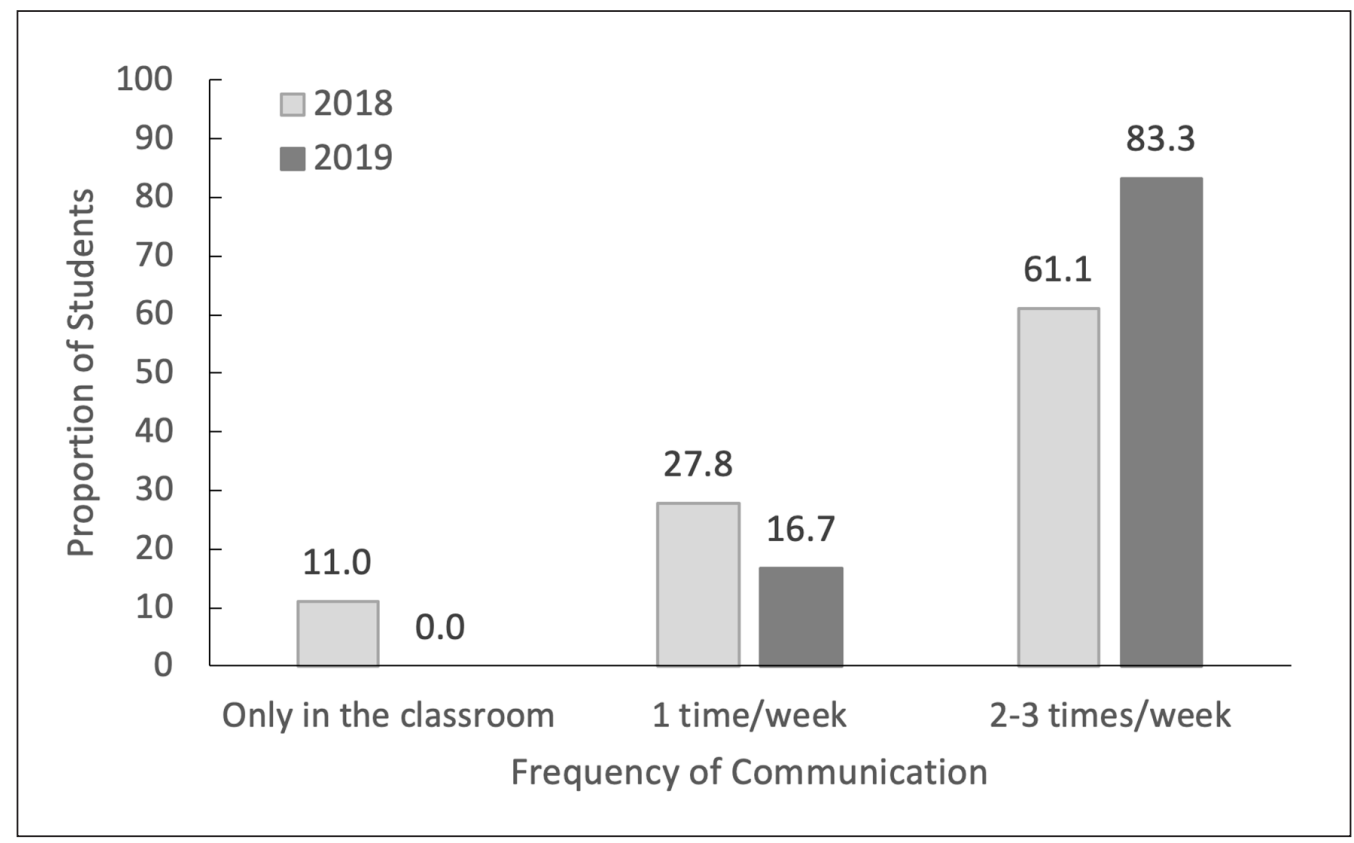


Figure 3. Distribution of students' answers to the question 'How would you describe the interaction in your team during the work on the joint project?'

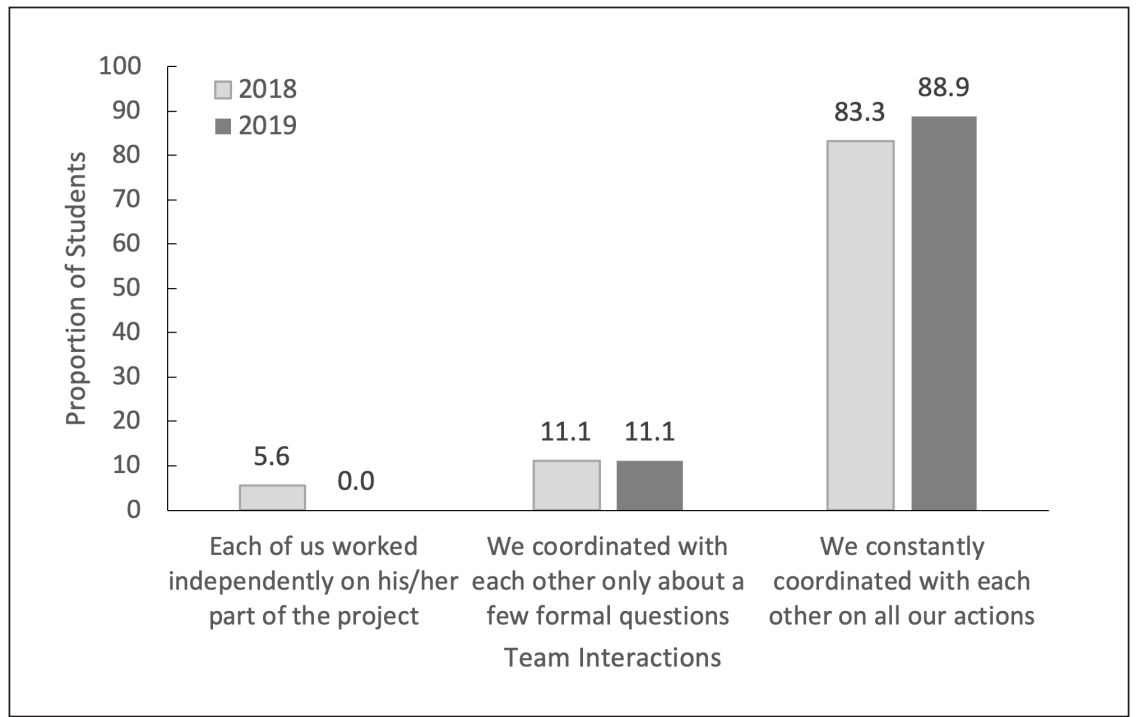

Figure 4. Distribution of students' answers to the question 'How would you rate the relations in your team?'

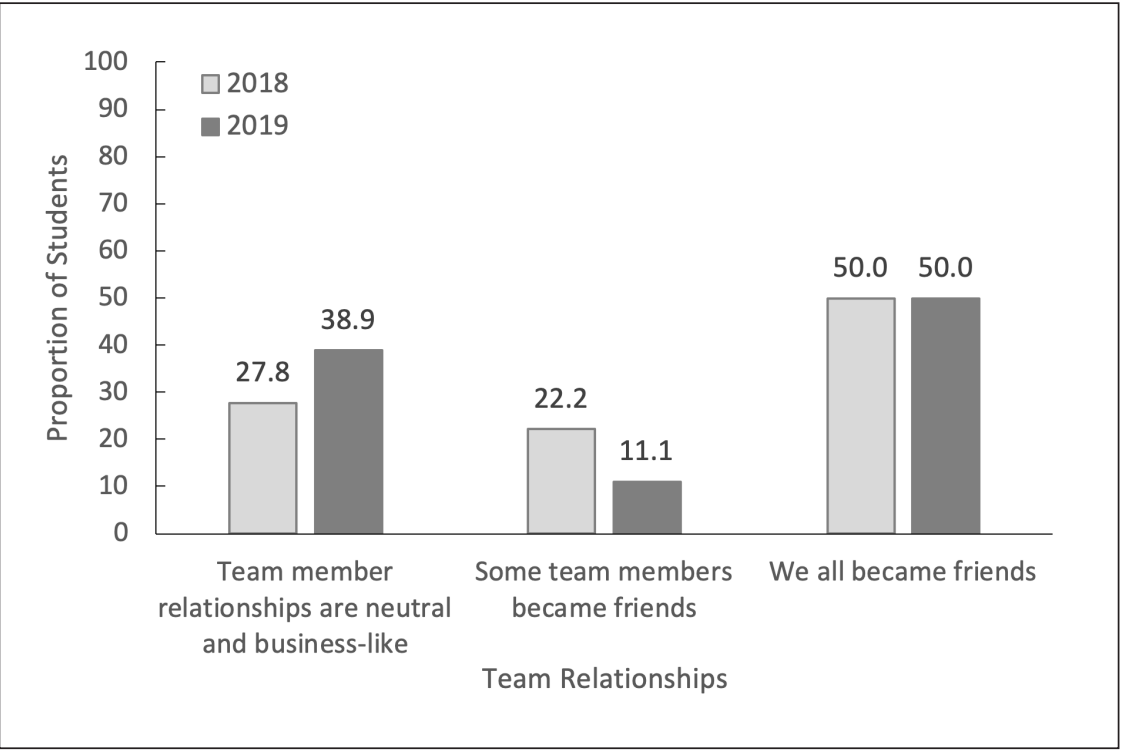




\section{Conclusion and implications}

Preliminary findings suggest that employing IIT (i.e. having students discuss native and non-native country media articles describing culture-specific perspectives on a global problem) increases the frequency of student interactions outside the classroom and improves coordination between teammates. Although we consider IIT as a tool for developing intercultural awareness, it is important to note potential limitations of this pilot project. The design of the study does not allow us to conclude that changes in the characteristics of interaction and relations in the teams are caused by the implementation of IIT and are not a consequence of initial differences in the individual characteristics of students. Further, we have not yet directly assessed intercultural awareness in the Global Leadership class. We first need to clarify which aspects of cultural awareness change as a result of the implementation of IIT.

When selecting an assessment of intercultural awareness, it is necessary to consider possible changes of two levels: (1) specific - awareness of cultural differences in relation to the discussed global problem; and (2) general - awareness of cultural differences in a broader context that can occur as a result of the use of IIT. For the first level, the object of assessment is the results of IIT; for example, answers to interview questions. Responses that include assumptions about possible differences in behavior in a culture-specific situation may indicate greater awareness than responses that negate or minimize these differences. Perhaps even students' reports about the impossibility of finding descriptions of culturally specific situations can be considered as an indicator of denial of cultural differences related to the chosen global problem. For the second level, the relevant object of assessment may be the personal experience of intercultural interaction received by students in Global Leadership. For a qualitative assessment, open-ended questions can be used similar to those described by Bennett (2017) to assess the perception of cultural differences; for example:

- Could you give an example of communication difficulties with your partners from a partner university when working on a collaborative project?

- What is an example of how you changed your behavior to communicate more effectively? How did you know what to do differently?

If the student speaks about the absence of difficulties, this may indicate a low level of awareness of cultural differences. These are only general prerequisites for the development of an assessment tool, which is a special task.

We plan to continue using IIT in the Global Leadership course. Given the obtained qualitative and quantitative results, we have several directions for future work: 
- to discuss the main characteristics of IIT at the beginning of the link classes, in order to make them more understandable for students;

- draw students' attention to the importance of choosing culturally specific situations and interviewing partners regarding their attitude to these situations; and

- to develop a tool for assessing the initial and final level of specific aspects of students' intercultural awareness which can be changed through COIL.

\section{References}

Bennett, M. (1986). A developmental approach to training intercultural sensitivity. In J. Martin (Guest Ed.), Special Issue on Intercultural Training, International Journal of Intercultural Relations, 10, 179-186.

Bennett, M. J. (2017). Developmental model of intercultural sensitivity. In Y. Y. Kim (Ed.), The international encyclopedia of intercultural communication (pp. 1-10). https://doi.org/10.1002/9781118783665.ieicc0182

Curtindale, L., \& Krylova, S. (2019) Teaching strategies for developing students' leadership and interaction skills through collaborative learning in intercultural virtual teams. Global Partners in Education Journal, 7(1), 26-43. http://www. gpejournal.org/index.php/GPEJ/article/view/127

EVALUATE Group. (2019). Evaluating the impact of virtual exchange on initial teacher education: a European policy experiment. Research-publishing.net. https://doi.org/10.14705/rpnet.2019.29.9782490057337

Festinger, L. (1957). A theory of cognitive dissonance. Stanford University Press.

Guth, S. (2014). Case studies from the COIL institute for globally networked learning in the humanities. SUNY COIL Institute. http://coil.suny.edu/sites/default/files/coil_institute_case_studies.pdf

Krylova, S., \& Curtindale, L. (2017, May). “Global Leadership”: Student experiences in virtual intercultural teams. Presented at Global Partners in Education Conference, Greenville, NC.

Mervosh, S. (2019). An unvaccinated boy got tetanus. His Oregon hospital stay: 57 days and \$800,000. https://www. nytimes.com/2019/03/09/well/oregon-child-tetanus-vaccine.html

Minyurova, S., Krylova, S., \& Rudenko, N. (2015) On-line videoconferences: how to make intercultural collaboration effective for all participants. Global Partners in Education Journal, 5(1), 27-37. http://www.gpejournal.org/index. $\mathrm{php} / \mathrm{GPEJ} / \mathrm{article} / \mathrm{view} / 74$

O’Dowd, R., \& Ritter, M. (2006) Understanding and working with 'failed communication' in telecollaborative exchanges. CALICO Journal, 61, 623-642.

Onishchenko, Y. (2019). The so-called viral parties are gaining popularity in Russia. https://www.1tv.ru/news/2019-0327/362600-v_rossi__nabirayut_populyarnost_tak_nazyvaemye_virusnye_vecherinki

ProQuest. (2019a). CultureGrams World Edition. Russia. http://online.culturegrams.com/

ProQuest. (2019b). CultureGrams World Edition. United States of America. http://online.culturegrams.com/ 


\section{Virtual Exchange?}

Published by University of Groningen Press | UGP, a not-for-profit press

Groningen, The Netherlands | UGP@rug.nl

(C) 2020 UNICollaboration (collective work)

(C) 2020 by Authors (individual work)

Journal of Virtual Exchange 2020

Edited by Carolin Fuchs and Müge Satar

Special issue edited by Penelope Margaret Orton, Natesha L Smith-Isabell, and Mary Jane Radford Arrow

Publication date: 2020/12/17

Journal of Virtual Exchange (JVE) is an online, open-access, peer-reviewed journal aimed at practitioners and researchers in the field known variously as virtual exchange, telecollaboration, or online intercultural exchange. It is the official journal of UNICollaboration (https://www.UNICollaboration.org/), the international academic organisation dedicated to supporting and promoting telecollaboration and virtual exchange in higher-level education.

Rights. The whole volume is published under the Attribution-NonCommercial-NoDerivatives 4.0 International licence (CC BY-NCND 4.0); individual articles may have a different licence. Under the CC BY-NC-ND licence, the volume is freely available online for anybody to read, download, copy, and redistribute provided that the author(s), editorial team, and publisher are properly cited. Commercial use and derivative works are, however, not permitted.

Disclaimer. University of Groningen Press does not take any responsibility for the content of the pages written by the authors of this article. The authors have recognised that the work described was not published before, or that it was not under consideration for publication elsewhere. While the information in this article is believed to be true and accurate on the date of its going to press, neither UniCollaboration nor University of Groningen Press can accept any legal responsibility for any errors or omissions. Additionally, the publisher makes no warranty, expressed or implied, with respect to the material contained herein. While University of Groningen Press is committed to publishing works of integrity, the words are the authors' alone.

Trademark notice. Product or corporate names may be trademarks or registered trademarks, and are used only for identification and explanation without intent to infringe.

Copyrighted material. Every effort has been made by the editorial team to trace copyright holders and to obtain their permission for the use of copyrighted material in this article. In the event of errors or omissions, please notify the publisher of any corrections that will need to by incorporated in future editions of this article.

Typeset by Research-publishing.net (https://research-publishing.net)

Noto fonts are open source. All Noto fonts are published under the SIL Open Font License, Version 1.1. Noto is a trademark of Google Inc. (https://www.google.com/get/noto/).

ISSN: 2647-4832 (online only)

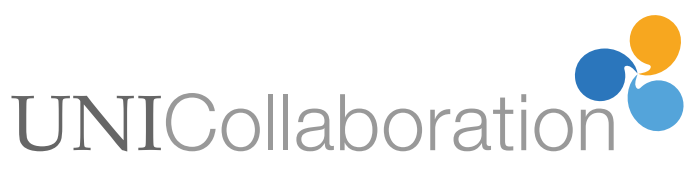

